\title{
Selective Translation of Idioms Translation in Journey to the West
}

\author{
Yin $\mathrm{Lu}$ \\ College of Information \& Business \\ Zhongyuan University of Technology \\ Zhenghzou, Henan, China
}

\begin{abstract}
Xi You Ji, the classical masterpiece of China, is well-known by its plentiful language and unique artistic style. Its theme, which is different to other classical fictions in China, relates to interflow of the worldwide cultural. There are plenty vivid idioms in $\mathrm{Xi}$ You $\mathrm{Ji}$ This makes $\mathrm{Xi}$ You Ji a treasure-house of idioms. $\mathrm{Xi}$ You $\mathrm{Ji}$ has become a window for the western academia to research Chinese cultural. The transmission of $\mathrm{Xi}$ You $\mathrm{Ji}$ in West is a very important case in literature compare between the East and the West and in cultural exchange. So far, there are only 2 fully English versions of Xi You Ji. One of them, Jenner's Journey to the West, is an achievement by an English speaker and scholar to translate and introduce Chinese ancient book into western culture. It means particularly in cultural exchange between China and the West.
\end{abstract}

Keywords—selective translation; idioms translation; Jenner's Journey to the West

\section{INTRODUCTION}

C-E translation of idioms is always a popular study object in translation study. The scholars have made many efforts to research idioms translation from various perspectives. To find an ideal translation method of idioms, many scholars have proposed different approaches. Research on vocabulary in $\mathrm{Xi}$ You Ji started from 1980s. But the related study on idioms translation in Xi You Ji could be hardly found.

It is acknowledged in academia that Xi You Ji [1] (with 100 chapters) was finished in medium and later stage of 16th century, Ming dynasty. Different with early novels in the vernacular Chinese, the language of $\mathrm{Xi}$ You $\mathrm{Ji}$ is vivid, fluency and sprightly. Ming dynasty is one of the rush hours that plenty of new idioms come into being. The novels at that time absorbed a mass of idioms which were verbally spread among the people. Many such idioms from various sources appeared also in Xi You Ji. Among plentiful idiomatic phrases, there are 480 idioms in $\mathrm{Xi}$ You Ji. [4]These idioms content a large amount of wisdom and cultural value of Chinese people. They are so charm because of "their graceful forms, large quantities, deep meanings and actual effect". [5] As linguistic data, they are extremely valuable.

British Sinologist Prof. W. J. F. Jenner (1940--) graduated from the Oxford and is engaged in sinology. He works at Department of East Asia, Leeds University, Britain. He also worked in Foreign Language Bureau of China before the Cultural Revolution. When he was in China, he translated Xi You Ji, which was pressed and published during 1980-1982 with the name Journey to the West [2]. This version is the first fully English version by an English native speaker.

Expressions of Chinese idioms are much briefer than those of English. Some words and phrases are useless in Chinese source text but necessary in English target text. Selective translation is designed on the basis of faithfulness to the source text, making it more fluent, smooth, and concise, thus conforming to idiomatic Chinese. In this case, translators apply it in order to make the target text more coherent and better understood by readers. "In selective translation only details relating to one specific aspect of source text are translated, thus eliminating all irrelevant information. Additional information not in the original document may be added in the form of explanatory notes, tables, graphs and so on, and the target language reader will thus have rapid access to the most important information contained in source text." $\left[{ }^{6]}\right.$

\section{FeATURES OF IDIOMS IN XI YOU JI}

Chinese idiom belongs to idiomatic phrase and is fixed word-combination in habitually use. Idiom is always composed with 4 words. The constitution of the words is various. Idioms have differed sources and are product of mentality, language and culture. There are abundant content about literature, historiography and philosophy in idioms which can correctly express complicated phenomenon with few words. The common vocabulary can not achieve the expression effect of idioms.

Generally, features of idioms are relative fixed form, intact and clear definite meaning, convention, historic of form, national characters in form and content. Except the general features as common idioms, the idioms in $\mathrm{Xi}$ You Ji possess their distinguishing features.

Firstly, most of Chinese idioms, as well the idioms in $\mathrm{Xi}$ You Ji, are formed with 4 words and they sound nice and smooth with obvious rhyme when they are read. "Four" is related to the Chinese temperament and interest on appreciation of the beauty. "Four" means square, the four seasons and also means integrity and perfect Feng Shuey. From ancient times to the present, four words corresponds the aesthetic habits of the Chinese. Examples of this case are very plentiful to be found in Xi You Ji.

Secondly, forms of Chinese idioms are always terse. Meanings of them are holistic meaning. Meaning of an idiom 
refers to not simply addition of the meaning of each word in an idiom, but the particular meaning of the words as a whole. In other words, meaning of an idiom is not its literal meaning but its implied and implicit meaning. For example:“金蝉脱 壳” describes a cicada leaving behind its cast-off part in molting. But this idiom means an escape by crafty scheme from an entangled situation or stratagem for slinking off.

Thirdly, idioms have a long history and definitely have characters of the nation which they belong to. Chinese idioms, as well the idioms in $\mathrm{Xi}$ You Ji, come into being from abroad and various sources. Many idioms derive from allusions, ancient books and records or continue to use spoken language and folk adage of front eras. “打草惊蛇”, which has very close meaning with the English idiom" to wake a sleeping dog", means "to beat the grass and frighten away the snake" or "act rashly and alert the enemy”. “三阳交泰”comes from The Book of Changes (I Ching). It is an auspicious sign and people use it to express good wished at the beginning of a new year.

Fourthly, the employment of idioms is established by the people through long social practice and always unvarying. Both their structural constitution and structural relationship are fixed in the long term of usage. We may not change any part of an idiom optionally. For instance:

“欢天喜地”, “犬马之劳” and “七损八伤” can not be changed into“欢天笑地”, “狗马之劳”or “五损六伤”

Structures of idioms in Xi You Ji are complicated and have full-scale progress. Some of the idioms which are from front eras were not settled until around the period in which Xi You Ji appeared. Such as: “火上弄冰” (445) was “火上弄冰凌”in Yuan dynasty.

Besides, structures of idioms in $\mathrm{Xi}$ You $\mathrm{Ji}$ are not very stability. It is very usual that one idiom has differed form. Some words in one idiom could be changed into a synonym, but their meanings will not change.

These phenomena declare that structures of idioms in literary output are relative stationary. Idioms develop and vary when they inherit from past. The features of idioms in Xi You $\mathrm{Ji}$ are the very reflect of development and variation of language at that period.

In the language system, idiom is the kinds of vocabulary which can vivid reflect cultural information and social life of human. These vocabularies with regular meanings and forms are unavoidable applied in cultural interchange. They are the most direct and terse expression of their own culture and tradition. Because of their character, cultural information that they contain, the differences of cultural background and mode of thinking between both sides of interflow, it is always a difficulty in translating activity that how to understand the exact meaning of idioms in source text and how to translate idioms correctly. And that is also one of the concerns in academia.

Idiom is provided with the comparability that the other ordinary vocabulary do not posses. They are the most direct and terse expression of their own culture and tradition.
Because of their character, cultural information that they contain, the differences of cultural background and mode of thinking between both sides of interflow, it is always difficult in translating activity to understand the exact meaning of idioms in source text and to translate idioms correctly.

\section{SELECTIVE TRANSLATION OF IDIOMS IN JOURNEY TO THE WEST}

The imitation relations between translation and culture are decided by the interrelations between language and culture. Idioms are one kind of carrier of culture, which record human civilization and social progress. The translator has to find out the cultural elements which the idioms contain and the deep understanding and analyses of both cultures that idioms represent.

Chinese idioms are phrases with ample cultural and language connotative. They possess distinct national features. Because of compact structures and incisive meanings of idioms, translation of idioms reflects obvious shock between differed culture on the aspects of language and culture in translation activities. Notable diversity historical and cultural background, traditional customs and way of thinking between two nations cause great diverse on image, sense, and usage of idioms.

Idioms, to a large degree, rely on specific social and cultural background. They are concise and comprehensive, vivid and ample. Idioms are a pithy language stuff which has obviously better expression force and more cultural intention. Linguist Hudson once said in his Sociolinguistics clearly, that many language features are as well as cultural features. Idioms, with rich national features, are also the part with greatest difference between two languages. [9] Different culture possesses different custom and value. So, translation of Chinese idioms can not be regarded as simple activity of language transition. Some idioms with profound and lasting cultural deposits could hardly be understood in other culture. Some idioms have no opposite terms in target language. It courses in translating untranslatable factors and brings a lot of difficulties.

$\mathrm{Xi}$ You Ji is an encyclopedia with extreme extensive and profound Chinese cultural features. To translate such a literature masterpiece, which contains abundant contents and fuses Confucianism, Buddhism and Taoism, the translators should have attainments of the following aspects: profound basis knowledge of Chinese culture, accomplishment of English literature and history of religions.

W. J. F. Jenner has both his own advantages to treat cultural factors in translation and a thorough knowledge of both western and traditional Chinese. But he has his own intention when he translated Xi You Ji into English. Fierce interest and attention to $\mathrm{Xi}$ You Ji gave Jenner great impetus. He wanted to introduce it perfectly to his fellow country people. Jenner had a fervent wish to share the pleasure of $\mathrm{Xi}$ You $\mathrm{Ji}$ with the target language readers. Jenner considered about how to make the text convenient for the readers to read and enjoy. He paid attention to character and expression effect of target language to serve the readers. Considering about the acceptance mentality of English readers, Jenner also made 
great efforts to reduce barrier of reading and understanding for them. He tried to make all the strange into familiar even some cultural factors of source text were lost.

In his postscript in Journey to the West, Jenner wrote: "Whatever the message may be, the best thing is not to worry about it, but simply to enjoy the book's wisdom, humor and endlessly rich observation and invention. If the reader can get some of the pleasure from Journey to the West that I have had in translating it the effort will not have been wasted." (1984)

There are over 800 thousands words in $\mathrm{Xi}$ You Ji. The language in it was common language at that time and also obvious dialect. Among plentiful idiomatic phrases, there are 480 idioms. These idioms content a large amount of wisdom and cultural value of Chinese people. Structures of idioms in $\mathrm{Xi}$ You Ji are complicated and have full-scale progress. Some of the idioms which are from front eras were not settled until around the period in which $\mathrm{Xi}$ You Ji appeared. Besides, structures of idioms in $\mathrm{Xi}$ You Ji are not very stability. It is very usual that one idiom has differed form. But their meanings will not change. Jenner ignored the disturbance and treated these idioms with two or more forms as one. For example:

\section{翻江摚海-搅海翻江:}

I can turn rivers upside down, stir up the sea,

...stirring up the sea, turning rivers upside down,

点石成金-点石为金:

and turn stones to gold with a touch.

: and turn stones to gold.

\section{翻天覆地-地覆天翻:}

I had to turn heaven and earth upside down...

... heaven and earth might be turned upside down.

Many idioms in English and in Chinese have opposite presentations in connotation and in extension. There are different conditions in these correspondences.

Literal correspondence. Some Chinese idioms could be translated according to literal meaning or use the similar English idioms with same analogy effect. Such as

变作三头六臂：... and grew three heads and six arms. hosts

一客不烦二主: A guest should not have to trouble two

Content correspondence. Some Chinese idioms have no opposite English idioms. But they could also be translated according to literal meaning and do not cause misunderstanding. Such as:

将计就计： ...beat him at his own game.

门当户对：...a very fitting son-in-law...

Correspondence on actual meaning. The literal meaning of some Chinese idioms could hardly be accepted and understood. The best method for translating these idioms is to translate their actual meaning. Such as

山恶人善: one's hearts are in the right place.

五黄六月：...it’s July and all crops are ripening,

Most idioms can not find an opposite English phrase to match up. For those idioms which contain allusions and national characters, it is hard to find close expression to reflect their meaning and background information. The most common way is literal translation in unavoidable conditions. Literal translation can convey the basic meaning of idioms, but the cultural information and analogy images of source language will be lost. However, this method keeps meaning and background of idioms, but it causes the text lengthy and the concise form of idioms is missing. In translating the sentences to pile up the aural, Jenner left out this part in order to make the text not so heavy and complicated.

Some idioms were translated in different ways in different sentences and context in order to carter to the thinking habit of English readers. Such as:

虚情假意:lied the demon,...

...put together a pack of lies as she replied,

...pretended to ...

背义忘恩: ...he had forgotten all feelings of decency and gratitude;

Ungrateful little beast!

欢天喜地: They were all very pleased,

...in high delight

山崩地裂/地裂山崩: as the mountain split open.

Mountains collapse and the earth

yawns open,

... an earthquake or a landslide,

情投意合: ...was finding him so congenial...

...is fond of him.

...we got on very well...

龇牙咧嘴: ... the Great Sage grimaced...,

pinched face, ...saw Monkey's producing teeth,

乐以忘忧: This cheered up Sanzang,

He forgot his worries...

密密层层: ...the layer upon layer of ...the many layers of

万籁无声: It's quiet now.

..., all was now silence.

Same idiom in different places can be translated in different ways. Some translation possesses a few same key 
words. For instance:

“天罗地网”--The key word in its translation is "nets":...heaven and earth nets...

...the net that held her

“剪草除根/斩草除根”-- there are 4 different translations:

I'll wipe him out for you.

...eradicate this evil weed...

cutting down weeds and digging them out by the roots.

.., to destroy them completely, root and branch,

“心惊胆战/胆战心惊”- Jenner translated “惊”into

"fear/terror/fright/shock" and “战” into " tremble/shake":

...he trembled with fear.

...shook with terror,

The news made all the spirits shake with fright.

..., trembling with shock.

...he trembled with fear,

Translation of Chinese idioms can not be regarded as simple activity of language transition. Some idioms with profound and lasting cultural deposits could hardly be understood in other culture. Some idioms have no opposite terms in target language. It courses in translating untranslatable factors and brings a lot of difficulties.

Jenner tried to make the target text easy to understand for the reader of target language. He employed fluency and transparent style to desalt the strangeness of source text with maximum efforts. His way of expression abided the tradition of target culture and language. Jenner tried to reduce the strange and unusual sense for English readers. And in order to explain the involved cultural phenomenon and history phrases, Jenner adopted notes, quotes and similar phenomenon in western culture to show the similarity between eastern and western culture.

Translation methods of idioms are flexible. One idiom could be translated in different methods. Proper translation is based on cultural background and acceptance of readers. Corresponding language between two languages and cultures could realize communication through recombination. In translating Chinese idioms, not only extension but cultural intensions are translated. Even semantic structures should be adjusted if necessary. However, untranslatable factors do not mean that idioms cannot be translated. Otherwise, the fascinating and splendid fragments in source texts will be boring in target texts. Even, the coherence of the text will be damaged and the text will be hard to read and understand.

There are 2 aims of idioms translation: to complete the cross-cultural communication activity and to visualize the abundant cultural information in idioms and deliver them. [7]The target text is an offer of information formulated by a translator in a target culture and language about an offer of information formulated by someone else in the source culture and language. [8] According to these rules, the standard of translation criticism is not equivalence, but how sufficient is the purpose which is realized by target text. The translator should choose translation strategies flexibly according to translation purpose and function of target text.

The way to deal with these idioms can deliver the meaning directly and never disturbs the readers. Translation purpose is mainly reflected in depose of every sentence and word of target text. The selection of translator can reflex their translation purpose. Through the analyses on translation of idioms in Journey to the West, this version is acceptable and owns fine effect.

\section{CONCLUSION}

The difference of culture reflected in difference of expression. Translation is a preceding offer of information. It is expected to bear some relationship with the corresponding source text. The source text is regarded as an "offer of information" from which a translator selects what is most useful and important to his translation purpose. Because of the features of Chinese idioms, Jenner had tried to keep and show Chinese culture to target receivers. He adopted more than one method to translate and introduce Chinese national culture and value. Jenner's translation of Chinese idioms kept foreign characters to some extent. He broke convention of target language and employed not fluency or transparent style to yield to the language features, absorb means of expression and retain culture of source text.

The key points in idiom translation are the literal meaning, content of images and extension or figurative meaning. But not all the idioms contain the 3 meanings at the same time. It is almost impossible to express all the 3 meanings in English. If there are contradictions between the 3 meanings in translating, extension or figurative meaning should be firstly kept. Sometimes the image in idiom should be changed. When there is no cultural conflicting, the literal meaning and content of images should be both considered. ${ }^{[10]}$ Because of the special national characteristics in Chinese literature, it is hard to understand and even to translate idioms correctly. That's obvious cultural barrier in translation. C-E translation of idioms is actually how to deal with various cultural features of idioms in English. According to different translation purposes, translators from specific cultural background adopt undoubtedly specific strategies and methods in disposing microcosmic cultural information of idioms in source text.

Various translation methods can appear in one version. Jenner's selections in idioms translation are based on his translation purpose. The methods for each detail are in order to achieve a specific purpose. Translation purposes of each detail may be different. But the translation purpose is reached through the difference and materialization. The functions and expectant aim of translation purposes for details and translation purposes for whole text are consistent.

$X i$ You $J i$ and its English versions are always studied by many scholars in the field of translation from different angles with various translation theories. Among these English versions, Jenner's Journey to the West is the only fully English version by an English native speaker. There are very 
few related studies on Journey to the West in China. It is regretful for the study on overseas spread of Xi You Ji. Translation of idioms could promote cultural exchange between China and the west. Translation of Chinese classical literature is an important way in spread of Chinese traditional culture to the west. Literature translation is firstly an exchange of two languages, but also deeply bases on a joint between two cultures. Through Journey to the West, it is found that there are still deficiency, misrepresentation and misunderstanding in the spread of Chinese culture in the west. At present, C-E translation of Chinese ancient books is still in its primary stage. Although some scholars have already turned their attention or are engaging in it, scientific theory systems and principle are still scarce. And not all the optimal elements are appropriate spread in the west. The spread is not original or constant. All of these should be improved in subsequent practice and studies.

\section{REFERENCES}

[1] Xi You Ji. Wu Chengen People's Literature Publishing House. 1980

[2] Journey to the West. W. J. F. Jenner Foreign Languages Press, Beijing, 1993

[3] Chinese Iidioms Dictionary. Sichuan Lexicon Publishing House. 1994.9

[4] Lexicological Research of Xi You Ji. Huang Jian. 2008

[5] Study of Structure and Culture in Translating Chinese Idioms into English. Yu Lianshun, etc. Heilongjiang University Publishing House. 2010.12

[6] Detionary of Translation Studies. Mark Shuttleworth \& Moira Cowie. Shanghai Foreign Language Education Press. 2004

[7] Translation of Chinese Idioms in the Perspective of Skopos Theory. Zhu Yiqun. Journal of Mudanjiang University. 2010.3

[8] Selected Readings of Contemporary Western Translation Theories. Ma Huijuan, Miao Ju. Foreign Language Teaching \& Research Press. 2009.4

[9] Study of English Idioms. Luo Shiping. Shanghai Foreign Language Education Press. 2006.1

[10] Cultural Diversity and Translation of Idioms in English and Chinese. Zhang Ning. Chinese Translators Journal. 1999.3 